\title{
REVISTA
}

\section{DISTRIBUIÇÃO E REPRESENTATIVIDADE FEMININA: UM ESTUDO SOBRE A UNIVERSIDADE ESTADUAL DO SUDOESTE DA BAHIA -UESB}

\author{
Ana Rocha Viana ${ }^{1}$ \\ Fernanda Pereira de Souza ${ }^{2}$ \\ Ma. Madalena Souza dos Anjos Neta3
}

RESUMO

O presente estudo teve como objetivo analisar a inserção da mulher no ensino superior, na Universidade Estadual do Sudoeste da Bahia - UESB. A metodologia utilizada foi uma pesquisa exploratória e descritiva, estudo de caso único. A classificação do delineamento dos procedimentos foram as pesquisas bibliográfica, para compreender o processo expansão da educação no Brasil e na Bahia; e a documental, com a coleta de dados junto a Secretaria Geral de Cursos e a Gerência de Assistência e Assuntos Estudantis. Após o levantamento, os dados receberam tratamento quantitativo e foram analisados à luz do referencial teórico. Os principais autores que nortearam este estudo foram: Martins (2014), Queiroz (2013), Santos (2014), entre outros. Os resultados demonstraram que na UESB, as mulheres representam maioria, especialmente, no campus de Jequié, muito pela característica dos cursos oferecidos, que são voltados para a área da saúde. Vitória da Conquista representa a maior equidade entre os gêneros na população discente, ainda assim, as mulheres correspondem a maior parte. Em Itapetinga, no ano de 2016, houve uma tendência de aumento da participação feminina como ocorreu em 2011 e 2012. No que diz respeito as áreas de conhecimento, foi percebido que a predominância feminina é nas ciências humanas e nas da saúde, as ciências exatas e da terra e as engenharias ainda é superior o número de homens. Os destaques positivos foram Engenharia de Alimentos, que apresentou presença forte de mulheres e o curso de Direito que contempla o maior nível de igualdade dos cursos ofertados na instituição.

Palavras - chave: Ensino Superior, Participação feminina, Educação.

\begin{abstract}
The present study aimed to analyze the insertion of women in higher education at the State University of the Southwest of Bahia - UESB. The methodology used was an exploratory and descriptive study, a single case study. The classification of the design of the procedures was the bibliographical research, to understand the expansion process of education in Brazil and Bahia; and the documentary, with the collection of data with the Secretary General of Courses and the Management of Assistance and Student Affairs. After the survey, the data received quantitative treatment and were analyzed in the light of the theoretical reference. The main authors that guided this study were: Martins (2014), Queiroz (2013), Santos (2014), among others. The results showed that in the UESB, women represent a majority, especially in the campus of Jequié, much to the characteristic of the courses offered, which are directed to the health area. Vitória da Conquista represents the highest gender equity in the student population, yet women account for the greater part. In Itapetinga, in the year 2016, there was a tendency to increase female participation, as occurred in 2011 and 2012. As far as the areas of knowledge were concerned, it was perceived that female predominance is in the human sciences and in health sciences, the exact sciences and the earth and engineering is still higher than the number of men.

\footnotetext{
${ }^{1}$ Graduanda em Administração (UESB). Email: anarochaviana@gmail.com

${ }^{2}$ Graduanda em Administração (UESB). Email: souzafernanda18@hotmail.com

${ }^{3}$ Professora Adjunta do Departamento de Ciências Sociais Aplicadas - DCSA da Universidade Estadual do Sudoeste da Bahia - UESB. madalena@uesb.edu.br
} 


\section{REVISTA}

\section{EXTENSÃO E CIDADANIA}

The positive highlights were Food Engineering, which presented a strong presence of women and the Law course that contemplates the highest level of equality of courses offered in the institution.

Key - words: Higher Education, Female participation, Education. 


\section{REVISTA}

\section{INTRODUÇÃO}

A educação foi o instrumento que proporcionou às mulheres a possibilidade da competição de forma igualitária com os homens, nos diversos setores da sociedade, principalmente, no mercado de trabalho. $\mathrm{O}$ acesso ao ensino é fator preponderante para alcançar a autonomia, uma vez que, as mulheres eram proibidas de estudar e deveriam se subordinar as figuras masculinas dos pais e maridos.

No decorrer da história, a sociedade sofreu e sofre muitas alterações nos diversos campos. A reavaliação das questões de gênero, por exemplo, tem levantado inúmeras discussões, em busca de um ambiente de oportunidades mais igualitário. Nesse sentido, as políticas públicas são instrumentos que favorecem a realocação de papéis em uma sociedade desigual e que, historicamente, coloca determinados grupos, em situação de marginalização.

Deste modo, a inserção da mulher no ensino superior perpassa por um caminho árduo de lutas e organização de movimentos sociais, para estabelecer que o direito ao acesso à educação seja cumprido. Deste modo, a política de cotas foi um importante elemento no que diz respeito à inclusão de grupos que sempre foram discriminados pela sociedade civil, pois, possibilitou o acesso não só as universidades, mas ao mercado de trabalho, através da garantia de cotas, também em concursos.

Nesta perspectiva, a mulher passa a ocupar espaços que, culturalmente, eram dominados pelo gênero masculino. Isto é um reflexo da sua autonomia, conquistada através do acesso à educação, que, teoricamente, possibilita a competição igualitária. No entanto, há o grande desafio da discriminação, porque mesmo com maiores níveis de qualificação, a sociedade, ainda considera o gênero como fator para desmerecer uma classe.

Segundo a Organização Mundial do Trabalho - OIT (2016), os principais fatores que contribuem para a manutenção de práticas discriminatórias são a subavaliação do trabalho, as competências exigidas nas profissões de predominância feminina e a necessidade das mulheres fazerem pausas na carreira para se dedicarem a responsabilidades adicionais. Em todo mundo, as mulheres trabalham mais do que os homens, ao se considerar as atividades não remuneradas, em média, os dias de trabalho correspondem a 73 e 33 minutos a mais por dia, respectivamente, nos países em 


\section{REVISTA}

desenvolvimento e nos países desenvolvidos. (OIT, 2016)

Ainda assim, a força feminina sustenta o enfretamento das lutas contra o preconceito. Deste modo, a população de mulheres que ingressam no ensino superior aumenta gradativamente, inclusive em áreas dominadas por homens. Segundo dados do Instituto Nacional de Estudos e Pesquisas Educacionais Anísio Teixeira - INEP, até 2013, o percentual médio de ingresso de alunas era de $55 \%$ do total em cursos de graduação presenciais. (MEC, 2015)

O estudo pretende investigar a participação feminina no ambiente acadêmico, da Universidade Estadual do Sudoeste da Bahia - UESB, para assim, avaliar quais as áreas do conhecimento apresentam maior participação feminina. Desta forma, compreender quais as profissões que ainda representam desigualdades de gênero no âmbito da universidade.

\section{EDUCAÇÃO DE MULHERES NO BRASIL}

A educação feminina é uma realidade recente, ao se considerar que a instrução da mulher era pautada para torná-las donas de casa e realizar o gerenciamento do lar e da família. Desta forma, durante um longo período, houve uma perpetuação da dependência e subordinação dos pais e maridos, uma vez que, eles tinham acesso à educação, ao mercado de trabalho e possuíam a função de chefiar as famílias. Santos (2014, p. 52) salienta que "as mulheres eram destinadas ao casamento, onde se tornariam donas de casa, mães e esposas dedicadas aos seus maridos, ao passo que os homens eram instruídos a serem principalmente advogados e médicos, buscando diferentes objetivos de ensino.”.

Historicamente, ocorrem discriminações de gênero advindas do período patriarcal, no qual os homens eram detentores do poder sobre as mulheres. Segundo Ribeiro (2003, p. 79), no período colonial, de 1500 a 1822, "tanto as mulheres brancas, ricas ou empobrecidas, como as negras escravas e as indígenas não tinham acesso à arte de ler e escrever", desta maneira, as de classes menos favorecidas tinham que realizar as atividades mais pesadas, como minério e agricultura, e as mais ricas, ficavam responsáveis pelos trabalhos domésticos. 


\section{REVISTA}

Ribeiro (2003, p. 79), salienta que a primeira mulher a saber ler e escrever foi Catarina Paraguassu, ela escreveu uma carta de próprio punho para Padre Manoel de Nóbrega, em 1561. No entanto, este foi um caso isolado, pois, ainda conforme a mesma autora, até 1627, somente duas mulheres de São Paulo sabiam assinar o nome, eram Leonor de Siqueira, viúva de Luiz Pedroso e sogra do Capitão-Mor Pedro Taques de Almeida, e Madalena Holsquor, viúva de Manuel Vandala, de origem flamenga.

A partir da chegada da Corte Portuguesa, a situação começou a mudar, segundo Martins (2014, p. 84).

A partir de um sentimento comum de que o século XIX representava para a sociedade burguesa o auge da civilização, todos pareciam concordar que não era mais possível aceitar que a população estivesse em situações tão opostas, pois enquanto uns detinham em torno de si todos os privilégios e poderes, outros viviam em uma absurda situação de inferioridade. (MARTINS, 2014, p. 84)

Esta nova perspectiva era baseada na aspiração de mudança trazida para o século XIX, o qual era amplamente visto como o início de uma civilização para a classe burguesa. Neste sentido, foi colocada a questão da educação as mulheres como instrumento de ajuda aos homens, para contribuir no progresso e participar das técnicas das ciências. (MARTINS, 2014, p. 85).

Após a Independência do Brasil, em 1822, surge uma nova realidade no país, mais complexa e que necessitava de esforços dos dirigentes. A educação passou a ser um instrumento de ascensão social, deste modo, houve um aumento na demanda, uma vez que, havia um forte movimento de imigração. Neste novo contexto, a educação feminina começa a ter um destaque, no entanto, com o intuito de favorecer a elite econômica. (MARTINS, 2014, p. 85).

A primeira legislação que contemplou a discriminação feminina ocorreu somente em 1827, foi a chamada Lei Geral, de 15 de outubro de 1827, a qual padronizou as escolas de ensino primário no Brasil. No entanto, as meninas não tinham os mesmos componentes curriculares dos meninos, elas eram ensinadas a aprender as 'artes do lar' e as prendas domésticas, por outro lado, os meninos aprendiam matérias consideradas mais racionais. 


\section{REVISTA}

Stamatto (2002, p.6) ainda salienta sobre o comportamento exigido para que as mulheres pudessem estudar e que se perpetuou por um longo período, uma vez que esta legislação serviu de modelo para as próximas leis.

A Lei Geral também solicitava que as mulheres fossem de 'reconhecida honestidade' e os homens 'sem nota de regularidade na sua conduta'. Com a descentralização do ensino levada a termo pela lei n.16 de 12 de agosto de 1834, a lei de 1827, serviria como modelo para as primeiras legislações provinciais a respeito do ensino primário. (STAMATTO, 2002, p. 6)

O ensino primário foi, durante muito tempo, a única opção para as mulheres. Somente em 1881, que por meio de um decreto imperial, as mulheres passaram a ter o direito a matrícula na educação superior. Rita Lobato Velho Lopes, iniciou esta nova realidade, ao ser a primeira mulher a obter o título de médica no Brasil, em 1887, pela Faculdade de Medicina da Bahia. (QUEIROZ, 2013, p. 1). Entretanto, foi um processo lento e que seguiu o movimento das cátedras, as mulheres vão começar a ter uma maior participação no ensino superior, na segunda metade do século XX.

Em pesquisa realizada nos arquivos das antigas escolas superiores que vieram a constituir mais tarde a Universidade de São Paulo [...] a primeira mulher a diplomar-se em Direito, ali, data de 1902. Somente nove anos depois, em 1911, registra-se a presença de mais uma mulher. Em 1918, as primeiras mulheres diplomam-se em Medicina no Estado. E a primeira mulher a freqüentar a Escola Politécnica de São Paulo somente vai fazê-lo em 1928. (QUEIROZ, 2013, p. 2)

Martins (2014, p. 86), afirma que a Revolução de 1930 foi um grande marco para os avanços da educação feminina, uma vez que, "ao redirecionar o desenvolvimento brasileiro para o mercado interno e para o setor urbano industrial, possibilitou a criação das primeiras políticas públicas de massa, de forma especial para as populações urbanas.”. Estas políticas públicas visavam democratizar o acesso e, desta maneira, possibilitar a expansão do ensino superior.

No início do século XI, a situação já demonstrava que as mulheres passaram a ocupar, de maneira intensiva, o espaço até então dominado pelo sexo masculino e o crescimento se mantém constante. O gráfico a seguir, com dados do último senso 


\section{REVISTA}

\section{EXTENSÃO E CIDADANIA}

demográfico, apresenta esta evolução, no período de 2001 a 2010.

Figura 1: Evolução da Participação Percentual de Matrículas em Cursos de Graduação (presencial e a distância) por Sexo - Brasil - 2001-2010

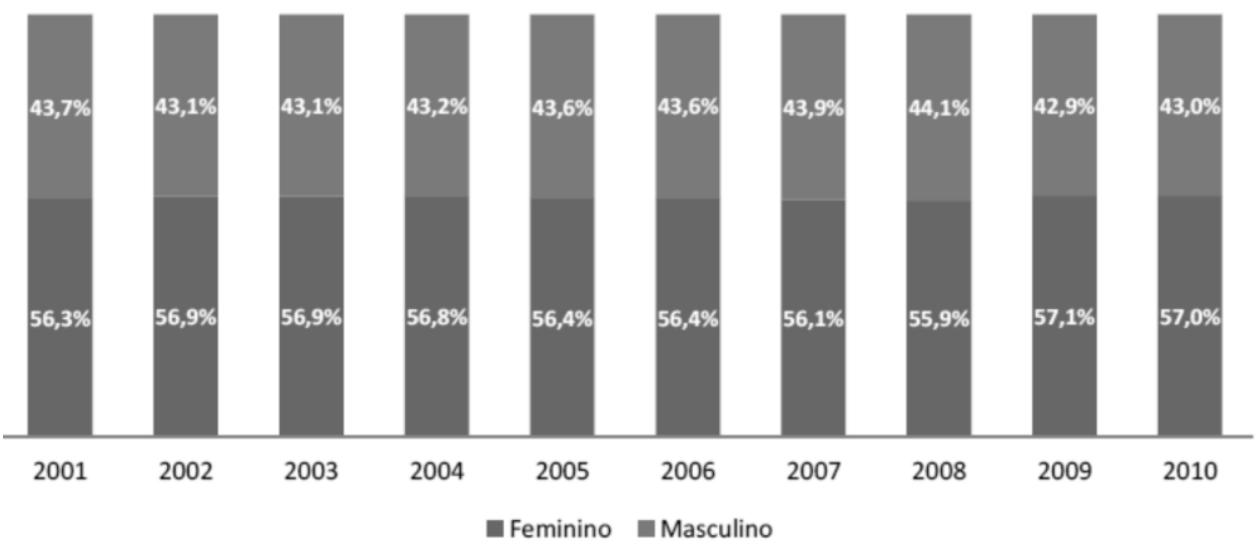

Fonte: MEC/Inep, 2011

No que diz respeito ao número de concluintes, as mulheres assumem uma vantagem ainda maior sobre os homens, os percentuais demonstram que mais da metade da população que conclui um curso superior, é do sexo feminino. Após o aumento da participação ocorrido nos anos de 1990, a tendência continuou na primeira década do século XXI, isto é representado pela pouca oscilação dos percentuais de concluintes do sexo feminino.

Figura 2: Evolução da Participação Percentual de Concluintes em Cursos de Graduação (presencial e a distância) por Sexo - Brasil - 2001-2010

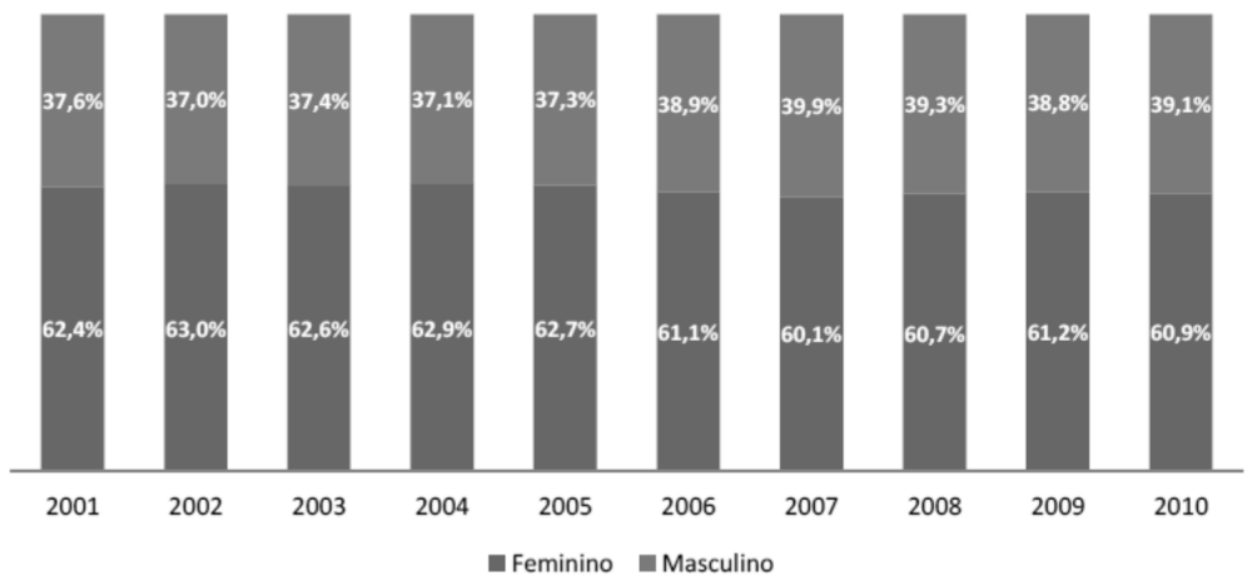

Fonte: MEC/Inep, 2011 
O aumento da participação feminina no ensino superior é reflexo da consolidação de direitos adquiridos pelas mulheres ao longo do tempo, neste sentido, as políticas públicas voltadas para a democratização do acesso, contribuíram efetivamente para que estes resultados fossem atingidos. As reformas e programas governamentais são instrumentos facilitadores da promoção da igualdade de oportunidades entre os gêneros.

Segundo informações do Censo da Educação Superior, divulgado em 2016, o perfil do discente da graduação no Brasil demonstra que há uma predominância de mulheres tanto na modalidade presencial quanto à distância. Além disso, o turno noturno é o que possui mais estudantes matriculados na modalidade presencial. A figura a seguir apresenta o perfil completo.

Quadro 1 - Perfil do vínculo discente nos cursos de graduação, por modalidade de ensino (presencial e a distância) - Brasil - 2015

\begin{tabular}{|l|c|c|}
\hline \multirow{2}{*}{$\begin{array}{c}\text { Atributos do Vínculo Discente } \\
\text { de Graduação }\end{array}$} & \multicolumn{2}{c|}{ Modalidade de Ensino } \\
\cline { 2 - 3 } & Presencial & a Distância \\
\hline Sexo & Feminino & Feminino \\
\hline Categoria Administrativa & Privada & Privada \\
\hline Grau Acadêmico & Bacharelado & Licenciatura \\
\hline Turno & Noturno & Não se aplica \\
\hline Idade (matrícula) & 21 & 33 \\
\hline Idade (ingresso) & 18 & 27 \\
\hline Idade (concluinte) & 23 & 33 \\
\hline
\end{tabular}

Fonte: INEP, 2016

A população feminina apresenta maior participação no ensino superior, entretanto, ao se considerar as áreas de conhecimento escolhidas por homens e mulheres, ainda ocorre uma primazia do sexo masculino entre as engenharias e ciências exatas. Como apresentado anteriormente, o número de mulheres que ingressaram e concluíram uma graduação é maior que o de homens, no entanto, ainda há uma incidência na escolha de cursos da área de humanas e saúde. A figura seguir demonstra 
essa realidade no ano de 2015.

Quadro 2: Os 10 cursos com maior número de matrículas por sexo - Brasil - 2015

\begin{tabular}{|l|r|}
\hline \multicolumn{1}{|c|}{ Curso } & Mulheres \\
\hline Pedagogia & 608.868 \\
\hline Direito & 471.674 \\
\hline Administração & 430.095 \\
\hline Enfermagem & 221.316 \\
\hline Ciências contábeis & 209.046 \\
\hline Psicologia & 181.314 \\
\hline Serviço social & 156.458 \\
\hline Gestão de pessoal / recursos humanos & 142.660 \\
\hline & \\
\hline Fisioterapia & 113.326 \\
\hline Arquitetura e urbanismo & 107.728 \\
\hline
\end{tabular}

\begin{tabular}{|l|r|}
\hline Curso & Homens \\
\hline Direito & 381.537 \\
\hline Administração & 336.764 \\
\hline Engenharia civil & 248.817 \\
\hline Ciências contábeis & 149.406 \\
\hline Engenharia mecânica & 116.573 \\
\hline Engenharia de produção & 111.653 \\
\hline Formação de professor de educação física & 98.737 \\
\hline Engenharia elétrica & 91.701 \\
\hline $\begin{array}{l}\text { Análise e Desenvolvimento } \\
\text { de Sistemas (Tecnólogo) }\end{array}$ \\
\hline Educação física & 73.077 \\
\hline
\end{tabular}

Fonte: INEP, 2016.

Conforme demonstrado no quadro 2, percebe-se que apesar do aumento da presença de mulheres inseridas no ensino superior, no que diz respeito às escolhas das áreas de conhecimento, não houve modificações significantes. Mesmo sem a ocorrência de discriminação quanto ao processo de ingresso, a equidade das preferências não existe, portanto, ainda há cursos que historicamente continuam com uma tendência masculina.

\section{METODOLOGIA}

Para analisar a inserção da mulher no ensino superior, foi realizada uma pesquisa exploratória e ao mesmo tempo descritiva. Para Gil (2002, p. 41 - 42), pesquisas exploratórias "têm como objetivo proporcionar maior familiaridade com o problema. [...] Pode-se dizer que estas pesquisas têm como objetivo principal o aprimoramento de idéias ou a descoberta de intuições". As descritivas "têm como objetivo primordial a descrição das características de determinada população ou fenômeno ou, então, o estabelecimento de relações entre variáveis.”.

A justificativa de um estudo exploratório-descritivo é pela necessidade de 


\section{REVISTA}

proporcionar mais informações sobre a presença da mulher no ensino superior, bem como descrever como é a realidade na Universidade Estadual do Sudoeste da Bahia UESB. A técnica estudo de caso se justifica pelo fato da investigação explorar como isto ocorre nos cursos de graduação da universidade. Uma vez que, segundo Yin (2001, p. 21), "como esforço de pesquisa, o estudo de caso contribui, de forma inigualável, para a compreensão que temos dos fenômenos individuais, organizacionais, sociais e políticos.”.

Foram utilizados os instrumentos de coletas de dados que proporcionassem os melhores resultados. A pesquisa bibliográfica, segundo Gil (2002, p. 44), “é desenvolvida com base em material já elaborado, constituído principalmente de livros e artigos científicos.". Ainda conforme o mesmo autor, a pesquisa documental, apesar de parecida com a citada anteriormente, esta possui uma diferença na natureza das fontes "Enquanto a pesquisa bibliográfica se utiliza fundamentalmente das contribuições dos diversos autores [...] a pesquisa documental yale-se de materiais que não recebem ainda um tratamento analítico, ou que ainda podem ser reelaborados de acordo com os objetos da pesquisa.".

Neste sentido, a pesquisa bibliográfica e a documental são as que apresentam as características necessárias para atingir o objetivo proposto. A primeira se justifica pela contextualização histórica da educação e como a mulher se inseriu no decorrer do tempo, a segunda foi utilizada para descrever a realidade da Universidade Estadual do Sudoeste da Bahia - UESB, a partir, da coleta feita no Plano de Desenvolvimento Institucional - PDI e em relatórios institucionais. A análise é quantitativa, posto que, a mensuração dos dados, foi realizada por meio da quantificação e do relacionamento entre as informações coletadas. Segundo Richardson (2015, p.70), esta "caracteriza-se pelo emprego da quantificação tanto nas modalidades de coleta de informações, quanto no tratamento delas por meio de técnicas estatísticas".

\section{RESULTADOS E DISCUSSÕES}

A Universidade Estadual do Sudoeste da Bahia - UESB possui três campi, localizados nas cidades de Itapetinga, Jequié e Vitória da Conquista e, atualmente, 
oferece 47 cursos de graduação, na modalidade presencial. Estes abrangem sete áreas de conhecimento: Ciências Exatas e da Terra; Engenharias; Ciências da Saúde; Ciências Agrárias; Ciências Sociais Aplicadas; Ciências Humanas e Artes. Estão divididos em bacharelados e licenciaturas e, nos cursos de pós-graduação, nos níveis Lato Sensu e Stricto Sensu, são oferecidos, ainda, 19 mestrados, 06 doutorados e 15 especializações. (UESB, 2017)

A instituição possui um corpo discente com 10.936 pessoas matriculadas, nos três campi, entre graduação e pós-graduação. Deste modo, para atender todas as demandas da universidade, num nível satisfatório e progressivo, o quadro de funcionários conta com 1.107 professores (entre pós-doutores, doutores, mestres e especialistas) e mais de 519 servidores (UESB, 2017).

A política de acesso aos cursos de graduação ocorre mediante o vestibular, realizado anualmente, e o Sistema de Seleção Unificada - SISU, com a utilização do princípio classificatório e de acordo com o número de vagas oferecidas. Existem ainda processos seletivos para cursos especiais e transferências internas, externas e ex-officio. (PDI/UESB, 2012, p. 13). No total são 2.015 vagas oferecidas nos 47 cursos de graduação divididas entre os campi de Vitória da Conquista, Jequié e Itapetinga.

Quadro 3 - Total dos cursos por campus

\begin{tabular}{|l|l|l|l|l|}
\hline \multirow{2}{*}{ CAMPUS } & \multicolumn{2}{c|}{ Modalidade } & \multirow{2}{*}{ Quantidade } & \multirow{2}{*}{ Vagas } \\
\cline { 2 - 5 } & \multicolumn{2}{|c|}{ Licenciatura } & \multicolumn{1}{c|}{ Bacharelado } & \\
\hline Vitória da Conquista & 10 & 12 & 22 & 1.065 \\
\hline Jequié & 8 & 8 & 16 & 660 \\
\hline Itapetinga & 4 & 5 & 9 & 290 \\
\hline Total Geral & $\mathbf{2 2}$ & $\mathbf{2 5}$ & $\mathbf{4 7}$ & $\mathbf{2 . 0 1 5}$ \\
\hline
\end{tabular}

Fonte: SGC/UESB, 2017

Com o objetivo de contribuir para a redução da exclusão social, $50 \%$ das vagas oferecidas pela universidade são destinadas ao programa de ações afirmativas, assim distribuídas: $70 \%$ para negros e $30 \%$ para os demais, com a exigência de terem cursado, no mínimo, do quinto ao nono ano do ensino fundamental e todo o ensino médio em escolas públicas. São acrescidas a todos os cursos, via cotas adicionais, três vagas para 


\section{REVISTA}

contemplar indígenas, quilombolas e pessoas com deficiência. (PDI/UESB, 2012, p. 13)

\section{OS INGRESSANTES DA UESB}

Com o objetivo de conhecer a participação feminina foi realizado um levantamento do número de discentes que ingressam na Universidade Estadual do Sudoeste da Bahia - UESB entre os anos de 2006 e 2016. Neste sentido, a análise será feita para investigar em quais cursos há uma maior participação das mulheres e em qual área ocorre à maior predominância do sexo feminino.

Os números demonstram que, nos últimos dez anos, as mulheres representam maioria entre os discentes que ingressaram na universidade e que essa tendência se acentua a partir do ano de 2009. Nos campi de Itapetinga e Vitória da Conquista a diferença não é tão expressiva como em Jequié, isto pode ser resultado dos tipos de cursos que são oferecidos no campus. O gráfico abaixo demonstra que há uma estabilidade quanto aos ingressos por sexo.

Gráfico 1 - Ingressantes por sexo nos três campi, da UESB, de 2006 a 2016

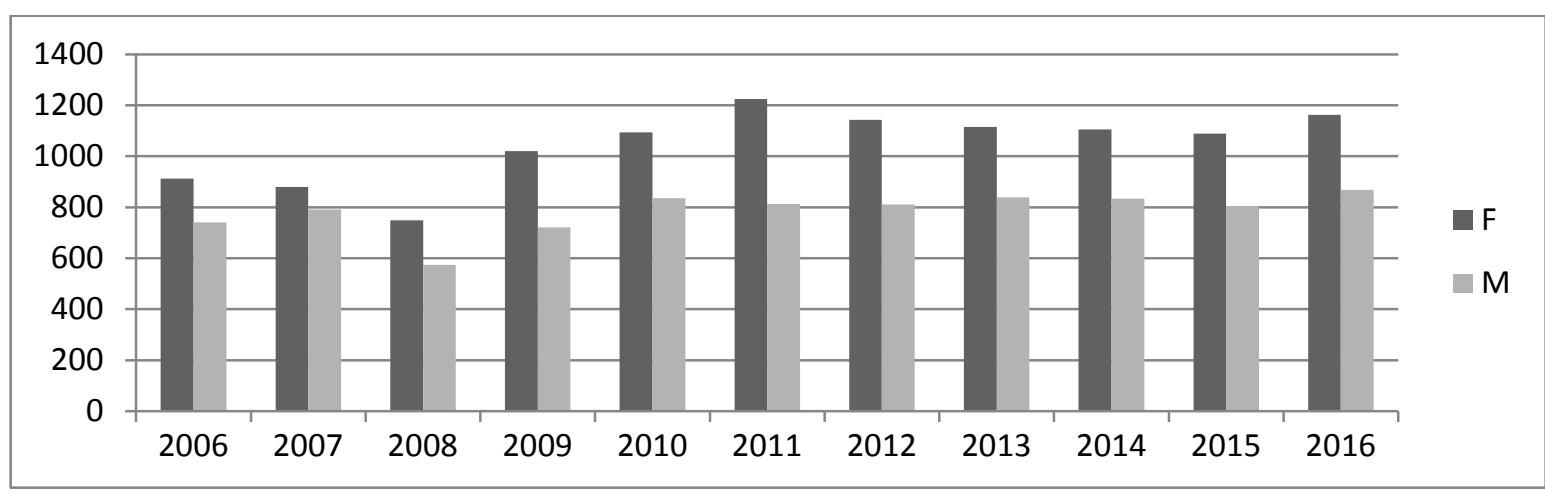

Fonte: SGC/UESB, 2017

Diante das informações acima, pode-se perceber que a partir de 2009 as mulheres começaram a aumentar a participação na UESB, posto que, entre os anos de 2006 e 2008 a diferença não era tão relevante. O ano de 2011 foi o mais expressivo em termos de participação feminina, as mulheres correspondiam a mais da metade, enquanto os homens representavam $40 \%$ dos discentes que ingressaram na instituição.

O gráfico 1 também apresenta que em 2016 houve um crescimento de ingressos em ambos os sexos, isto ocorre em razão do número de inscritos nos processos seletivos 


\section{REVISTA}

ter aumentado, logo, muitas vagas que ficavam ociosas em alguns cursos foram preenchidas. A redução em 2015 também é relacionada ao número de inscritos nos processos seletivos, uma vez que neste ano houve uma queda na participação.

\section{IGRESSANTES POR ÁREA DE CONHECIMENTO}

A universidade oferta cursos em sete áreas de conhecimento, as quais são: artes, ciências agrárias, ciências da saúde, ciências exatas e da terra, ciências humanas, ciências sociais aplicadas e engenharias. Desta forma, nesta seção serão apresentadas informações quanto aos ingressantes por sexo em cada uma das áreas oferecidas, no período que abrange 2014 a 2016.

Gráfico 2: Ingressantes por área de conhecimento, de 2014 a 2016, da UESB

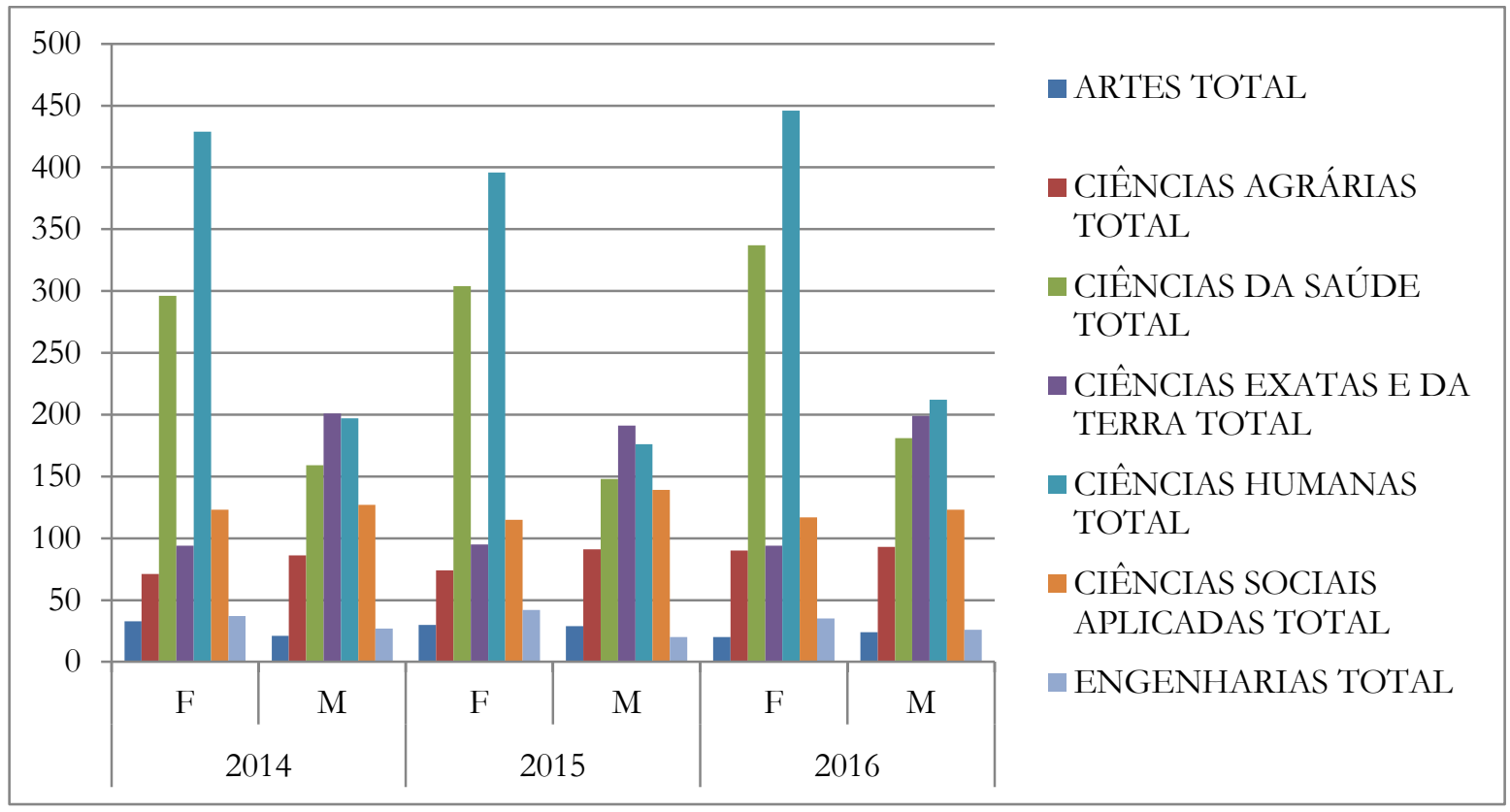

Fonte: SGC/UESB, 2017

Diante das informações coletadas, pode-se observar que as áreas em que há uma maior predominância de mulheres em relação a participação masculina são as ciências da saúde e ciências humanas. Em contrapartida, apesar de haver um aumento da participação feminina em diversos cursos, os que dizem respeito às ciências exatas e da terra e engenharias, ainda tem presença muito mais representativa de homens.

A desconstrução de papéis na sociedade ainda é lenta, neste sentido, as mulheres 


\section{REVISTA}

continuam ligadas a profissões que remetem ao cuidado e as relações interpessoais. No quantitativo geral da população discente, o sexo feminino detém vantagem significativa, no entanto, a distribuição por área e curso ainda demonstra os efeitos das relações de gênero.

Na UESB, Pedagogia, licenciatura em Biologia, Enfermagem, Fisioterapia, Odontologia, Ciências Sociais, Psicologia e Letras ainda representam os cursos com maior domínio feminino, em contrapartida, a Engenharia de Alimentos apresenta uma participação expressiva de mulheres, apesar de estar inserida em um campo tipicamente masculino. A área das ciências sociais aplicadas revela o maior nível de equidade na ocupação das vagas da instituição, apesar que em 2015 houve um crescimento do número de homens, em 2016 essa tendência não se fortaleceu.

$\mathrm{Na}$ perspectiva das carreiras tradicionais, advindas do período Imperial, em que foram criadas as cátedras, os cursos de Direito e Medicina apresentam igualdade de gênero e ampla participação feminina respectivamente. Entretanto, as Engenharias Agronômica, Ambiental e Florestal tem uma crescente parcela de mulheres, mas ainda perpetua a maior incidência de homens na composição de suas turmas.

$\mathrm{Na}$ área de ciências exatas e da terra, a predominância masculina não se alterou. Destacam-se os cursos tecnológicos, Ciências da Computação, Matemática com enfoque em Informática e Sistemas de Informação como os portadores da maior desigualdade de gênero. Há uma estabilidade no preenchimento destas vagas no que diz respeito ao sexo do indivíduo, posto que, há uma visão de que os homens possuem racionalidade elevada, além de receberem os estímulos para se interessarem por tecnologia desde crianças, diferentemente das mulheres.

Toda essa realidade dos cursos da universidade demonstra que as mulheres são a maioria no ensino superior, entretanto, apesar deste avanço, a população feminina ainda enfrenta diversas dificuldades para assegurar igual acesso, participação e progressos no mercado de trabalho. Segundo a Organização Internacional do Trabalho - OIT, as mulheres, em nível global, ganham cerca de $23 \%$ a menos do que os homens, mesmo quando apresentam a mesma escolaridade. Ainda conforme a OIT, esta diferença é fruto da subavaliação do trabalho feminino e de práticas discriminatórias. 


\section{O VESTIBULAR E O SISTEMA DE SELEÇÃO UNIFICADA}

A Universidade Estadual do Sudoeste da Bahia - UESB conta com duas formas de ingresso aos cursos de graduação; o vestibular realizado anualmente e, desde 2012, passou a utilizar também o Sistema de Seleção Unificada - SISU. Desta maneira, as vagas oferecidas pela instituição são divididas igualmente, $50 \%$ via vestibular e $50 \%$ pelo SISU. A tabela a seguir demonstrará como é a participação feminina nas duas formas de seleção para ingressar na universidade.

Tabela 1 - Quantitativo de ingressantes por sexo via vestibular e SISU, de 2012 a 2016

\begin{tabular}{|c|c|c|c|c|c|c|c|c|c|c|c|c|c|c|c|}
\hline \multirow{3}{*}{$\begin{array}{c}\mathrm{AN} \\
\mathrm{O}\end{array}$} & \multicolumn{5}{|c|}{ Vitória da Conquista } & \multicolumn{5}{|c|}{ Jequié } & \multicolumn{5}{|c|}{ Itapetinga } \\
\hline & \multicolumn{2}{|c|}{$\begin{array}{c}\text { Vestibula } \\
\text { r }\end{array}$} & \multicolumn{2}{|c|}{ SISU } & \multirow{2}{*}{$\begin{array}{c}\text { TOTA } \\
\mathrm{L}\end{array}$} & \multicolumn{2}{|c|}{$\begin{array}{c}\text { Vestibula } \\
\text { r }\end{array}$} & \multicolumn{2}{|c|}{ SISU } & \multirow{2}{*}{$\begin{array}{c}\text { TOTA } \\
\text { L }\end{array}$} & \multicolumn{2}{|c|}{$\begin{array}{c}\text { Vestibula } \\
\text { r }\end{array}$} & \multicolumn{2}{|c|}{ SISU } & \multirow{2}{*}{$\begin{array}{c}\text { TOTA } \\
\text { L }\end{array}$} \\
\hline & $\mathbf{F}$ & M & $\mathbf{F}$ & $\mathbf{M}$ & & $\mathbf{F}$ & $\mathbf{M}$ & $\mathbf{F}$ & $\mathbf{M}$ & & $\mathbf{F}$ & $\mathbf{M}$ & $\mathbf{F}$ & $\mathbf{M}$ & \\
\hline & & & 26 & 22 & & & & 19 & 10 & & & & 10 & 5 & \\
\hline \multirow[t]{2}{*}{2012} & 264 & 258 & 5 & 1 & 1008 & 208 & 124 & 4 & 3 & 629 & 102 & 53 & 9 & 2 & 316 \\
\hline & & & 23 & 24 & & & & 15 & 10 & & & & & 5 & \\
\hline \multirow[t]{2}{*}{2013} & 324 & 264 & 8 & 2 & 1068 & 223 & 106 & 5 & 8 & 592 & 86 & 66 & 88 & 3 & 293 \\
\hline & & & 25 & 22 & & & & 17 & 11 & & & & & 6 & \\
\hline \multirow[t]{2}{*}{2014} & 322 & 249 & 7 & 0 & 1048 & 210 & 125 & 1 & 0 & 616 & 86 & 66 & 59 & 4 & 275 \\
\hline & & & 25 & 22 & & & & 16 & 11 & & & & & 5 & \\
\hline \multirow[t]{2}{*}{2015} & 305 & 253 & 0 & 4 & 1032 & 235 & 100 & 4 & 7 & 616 & 86 & 57 & 62 & 5 & 260 \\
\hline & & & 25 & 21 & & & & 17 & 13 & & & & & 6 & \\
\hline 2016 & 299 & 249 & 0 & 9 & 1017 & 234 & 131 & 5 & 9 & 679 & 107 & 67 & 98 & 0 & 332 \\
\hline
\end{tabular}

Fonte: SGC/ UESB, 2017

No tocante as formas de ingresso, também ocorre a predominância da população feminina, tanto pelo acesso via vestibular quanto pelo SISU. As informações demonstram que, no geral, o principal meio para ingressar na universidade ainda é o concurso vestibular, sobretudo no campus de Jequié, onde a diferença entre as ingressantes por vestibular e SISU apresenta certa relevância.

Conforme as informações coletadas, pode-se observar que a universidade absorve mais discentes via exame vestibular, independente do sexo. Apesar de haver 


\section{REVISTA}

uma divisão por igual das vagas oferecidas entre as duas formas de ingresso, $54 \%$ dos alunos da UESB, nos últimos cinco anos, entraram na instituição através do vestibular e, deste percentual apresentado, $32 \%$ é de mulheres, o que representa mais da metade dos ingressantes.

\section{O SISTEMA DE COTAS DA UESB}

Com o objetivo de reduzir a discriminação de classes historicamente desfavorecidas, a Universidade Estadual do Sudoeste da Bahia - UESB destina 50\% das vagas oferecidas ao programa de ações afirmativas, distribuídas da seguinte forma: $70 \%$ para negros e $30 \%$ para os demais, ainda são acrescidas a todos os cursos, via cotas adicionais, três vagas para contemplar indígenas, quilombolas e pessoas com deficiência. (PDI/ UESB, 2012)

Gráfico 3: Ingressantes por cotas e sexo, de 2012 a 2016

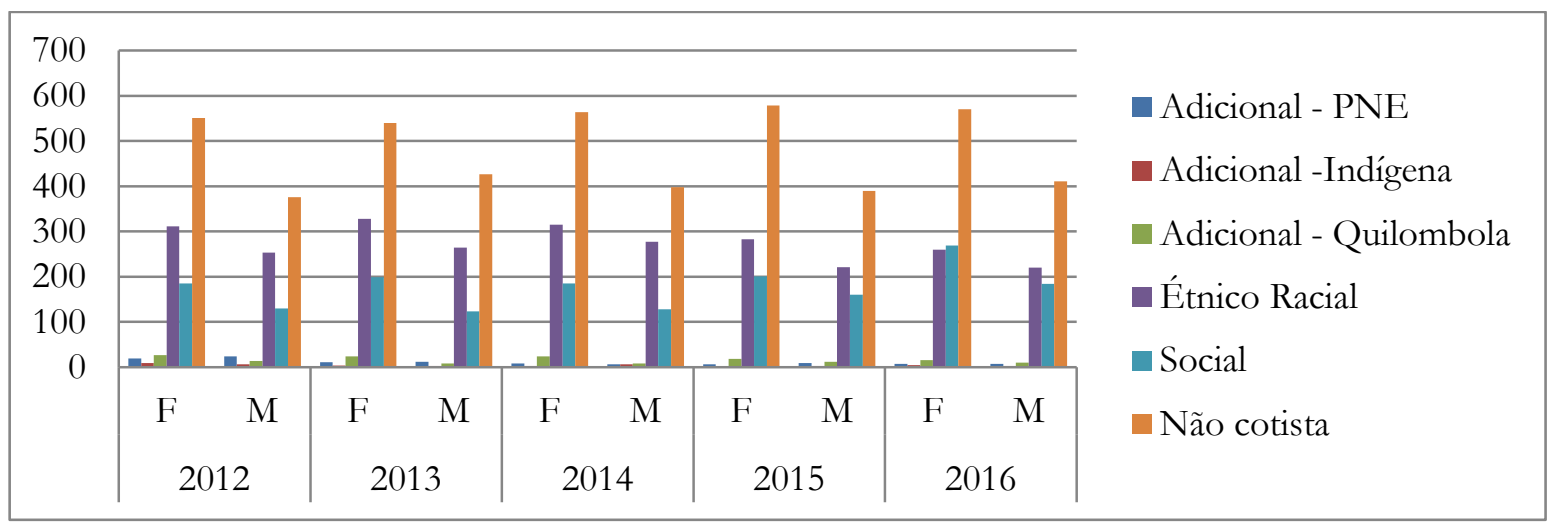

Fonte: SGC/ UESB, 2017

Nos três campi, o número de discentes que optam por cotas apresenta uma pequena superioridade da população feminina, isto é reflexo da característica da população discente da universidade, que é de mulheres. No campus de Vitória da Conquista, ocorre uma equidade de gênero e isto também é percebido em relação às cotas, em Jequié, campus com maior representação feminina, a diferença entre cotistas homens e mulheres é significativa, esta tendência é sentida da mesma maneira no campus de Itapetinga.

As cotas étnicos raciais demonstram que esta ação é um meio que facilita o ingresso de mulheres negras na universidade. O gráfico 3 apresenta que nos três campi 


\section{REVISTA}

há um número elevado de mulheres que optam pelas cotas raciais, no entanto, em Vitória da Conquista, nos anos de 2012 e 2014, a participação masculina foi maior do que a feminina, especialmente em 2012, que os homens representaram 55\%.

\section{CONSIDERAÇÕES FINAIS}

Nos últimos anos a discussão sobre as questões de gênero tem sido cada vez mais freqüentes, neste sentido, fica evidenciado o papel da mulher dentro da sociedade e todas as conquistas já alcançadas. No que diz respeito ao mercado de trabalho, a Organização Internacional do Trabalho - OIT apresenta que apesar das mulheres estarem mais qualificadas, isto não se reflete em maior participação em cargos elevados nas organizações. Toda essa realidade demonstra que mesmo com o avanço no acesso ao ensino superior, ainda assim, ocorrem discriminações nas áreas de conhecimento e, isto incide no mercado de trabalho.

O estudo realizado demonstra que na UESB há predominância de mulheres nos cursos de graduação, entretanto, a análise mais aprofundada, que considera a situação de cada curso da instituição apresenta que ainda não ocorre a equidade de gênero em todas as áreas. Principalmente no que tange aos cursos tecnológicos, a participação feminina ainda é incipiente, muito disso diz respeito à característica das escolhas, pois, as mulheres continuam como maioria, nas áreas das ciências humanas e ciências da saúde.

Os resultados obtidos corroboram de que a UESB segue a mesma tendência de participação feminina do país, em que as mulheres representam maioria nas instituições de ensino superior. No entanto, a dinâmica da formação do gênero feminino ainda perpassa pela questão social, uma vez que, os cursos com maior incidência são aqueles com baixo valor econômico, como é o caso das licenciaturas, especialmente a pedagogia. Vale destacar também duas grandes graduações que apresentam uma equidade, tanto no contexto do Brasil quanto da UESB, que são os cursos de Administração e Direito.

A pesquisa demonstrou que apesar da expansão de oportunidades para o ensino superior registradas no Brasil, e a UESB está inserida neste processo, as desigualdades ainda são presentes. Elas aparecem de diferentes maneiras, as relações de gênero são 


\section{REVISTA}

\section{EXTENSÃO E CIDADANIA}

exemplos disso, uma vez que, persistem dentro do campo educacional, mesmo sem haver discriminações no processo de inserção, ainda existem cursos que historicamente são dominados pelo sexo masculino. 


\section{REVISTA}

\section{EXTENSÃO E CIDADANIA}

\section{REFERÊNCIAS}

BRASIL. Ministério da Educação. Censo da Educação Superior 2010. Brasília: INEP/MEC, 2011. Disponível em:

<http://download.inep.gov.br/educacao_superior/censo_superior/documentos/2010/divu lgacao_censo_2010.pdf>. Acesso em: 20 maio 2017.

Ministério da Educação. Censo da Educação Superior 2015. Brasília:

INEP/MEC, 2016. Disponível em:

<http://download.inep.gov.br/educacao_superior/censo_superior/apresentacao/2015/Apr esentacao_Censo_Superior_2015.pdf>. Acesso em: 20 nov 2017.

Ministério da Educação. Censo Escolar da Educação Básica 2016. Brasília: INEP/MEC, 2016. Disponível em:

<http://download.inep.gov.br/educacao_basica/censo_escolar/notas_estatisticas/2017/no tas_estatisticas_censo_escolar_da_educacao_basica_2016.pdf >. Acesso em: 20 maio 2017.

GIL. Antônio Carlos. Como Elaborar Projetos de Pesquisa. 4. Ed. - São Paulo: Atlas, 2002.

MARTINS, Mariele. A expansão da educação superior brasileira: diferentes oportunidades, segundo a origem social e diferentes percursos, segundo o gênero. 2014. Dissertação (Mestrado em Programa de Pós-Graduação em Educação) - Universidade Federal de Santa Catarina. Florianópolis. Disponível em: <http://https://repositorio.ufsc.br/xmlui/bitstream/handle/123456789/130960/332268.pd f? sequence=1\&isAllowed=y >. Acesso em: 03 abr. 2017.

\section{ORGANIZAÇÃO INTERNACIONAL DO TRABALHO, Mulheres no}

trabalho. Genebra, 2016. Disponível em: <http://www.ilo.org/wcmsp5/groups/public/--dgreports/---dcomm/---publ/documents/publication/wcms_457096.pdf >. Acesso em: 15 nov. 2017.

QUEIROZ, Delcele Mascarenhas. (2013), Mulheres no Ensino Superior no Brasil. Programa de Pós-Graduação em Educação da UFBa. [Tese de Doutorado]. Disponível em: < http://23reuniao.anped.org.br/textos/0301t.PDF>. Acesso em 22 mar. 2017.

RIBEIRO, Arilda Inês Miranda. Mulheres educadas na colônia. In: LOPES, Eliane Marta Teixeira; FARIA FILHO, Luciano Mendes; VEIGA, Cynthia Greive (Org.). 500 anos de educação no Brasil. Belo Horizonte: Autêntica, 2003.

RICHARDSON, R. J. Pesquisa social: métodos e técnicas. 3. ed. São Paulo: Atlas S.A., 2015.

SANTOS, Maíra Barbosa. A participação das mulheres no ensino superior. Revista 
Três Pontos, Belo Horizonte, v. 11, n. 1, p.47-59, 2014. Disponível em: $<$ https://seer.ufmg.br/index.php/revistatrespontos/article/viewFile/2660/2036>. Acesso em: 22 mar. 2017.

STAMATTO, Maria Inês Sucupira. Um olhar na história:: a mulher na escola. In: CONGRESSO BRASILEIRO DE HISTÓRIA DA EDUCAÇÃO, 2., 2002, Natal, Rn. Anais... . Natal, Rn: Sbhe, 2002. p. 1 - 11. Disponível em: $<$ http://sbhe.org.br/novo/congressos/cbhe2/pdfs/Tema5/0539.pdf>. Acesso em: 25 maio 2017.

UNIVERSIDADE ESTADUAL DO SUDOESTE DA BAHIA. Plano de desenvolvimento institucional 2013-2017. Disponível em:

<http://www.uesb.br/pdi/arquivos/PDI_Final.pdf >. Acesso em 25 jul. 2016.

Dados da graduação. Disponível em:

<http://www.uesb.br/catalogo/pe.asp?cod=30>. Acesso em: 25 jul. 2017.

YIN, R. K. Estudo de caso: planejamento e métodos. 2. ed. Porto Alegre: Bookman, 2001.

Data de recebimento: 09/08/2017

Data de aprovação: 15/03/2018 